\title{
Systematic review and meta-analysis of extended high-frequency audiometry in tinnitus patients
}

\author{
Fan Peng ${ }^{1}$, Yuanhua Xiang ${ }^{2}$, Haitian $\mathrm{Xu}^{1}$, Qing Yin ${ }^{1}$, Jun $\mathrm{Li}^{1}$, Yuhua Zou ${ }^{3}$ \\ ${ }^{1}$ Otolaryngology, Taizhou Central Hospital (Taizhou University Hospital), Taizhou, China; ${ }^{2}$ Otolaryngology, Taizhou Hospital of Zhejiang Province, \\ Affiliated to Wenzhou Medical University, Wenzhou, China; ${ }^{3}$ Otolaryngology, Taizhou First People's Hospital, Taizhou, China \\ Contributions: (I) Conception and design: F Peng, H Xu; (II) Administrative support: Y Xiang; (III) Provision of study materials or patients: F Peng, Y \\ Xiang, H Xu, Q Yin, Y Zou; (IV) Collection and assembly of data: All authors; (V) Data analysis and interpretation: F Peng, Q Yin, J Li, Y Zou; (VI) \\ Manuscript writing: All authors; (VII) Final approval of manuscript: All authors. \\ Correspondence to: Yuhua Zou. Taizhou First People's Hospital, No.218 Hengjie Road, Huangyan District, Taizhou, China.
}

Email: zouyuhua_1990@126.com.

Background: This study aimed to systematically evaluate the detection effect of extended high-frequency audiometry (EHFA) in tinnitus patients and provide a theoretical basis for the clinical diagnosis of tinnitus.

Methods: We conducted a computer-based search for randomized controlled trial (RCT) literature on extended audiometry in tinnitus patients using the PubMed, Web of Science, China National Knowledge Infrastructure (CNKI), and Elsevier Science Direct databases. The search dates ranged from the database establishment date to February 2020. Risk of bias in the included literature was evaluated using the RCT bias risk assessment standard provided in the Handbook for Systematic Reviews for Interventions (version 5.0.2, 2008, Chapter 9). Finally, Review Manager 5.3 software was used to conduct a meta-analysis of the included literature.

Results: The retrieved literature was systematically screened. A total of 10 RCTs were included in the meta-analysis, which involved a total of 1,389 tinnitus patients. The results of the meta-analysis showed that at the frequencies of $14 \mathrm{kHz}$ and $16 \mathrm{kHz}$, there was visible difference in detection rate of hearing threshold (DR-HT) between the 2 groups [odds ratio $(\mathrm{OR})=0.21,95$ confidential interval (CI): 0.14-0.32, Z=7.29, $\mathrm{P}<0.00001]$ and $(\mathrm{OR}=0.14,95 \% \mathrm{CI}: 0.07-0.27, \mathrm{Z}=5.96, \mathrm{P}<0.00001)$ respectively. When the frequency was $18 \mathrm{kHz}$, there was a significant statistical difference in DR-HT between the 2 groups $(\mathrm{OR}=0.13,95 \% \mathrm{CI}$ : $0.07-0.24, \mathrm{Z}=6.50, \mathrm{P}<0.00001)$, and at $20 \mathrm{kHz}$, the statistically significant difference in DR-HT between the 2 groups was high (OR =0.17, 95\% CI: $0.12-0.23, \mathrm{Z}=10.38, \mathrm{P}<0.00001)$.

Discussion: EHFA had a critical effect on tinnitus patients. The meta-analysis provided evidence for early hearing loss in tinnitus patients. EHFA played a crucial role in the clinical diagnosis of tinnitus patients.

Keywords: Meta-analysis; tinnitus; extended high-frequency audiometry (EHFA); detection rate of hearing threshold

Submitted Sep 14, 2021. Accepted for publication Nov 17, 2021.

doi: 10.21037/apm-21-3060

View this article at: https://dx.doi.org/10.21037/apm-21-3060

\section{Introduction}

Tinnitus is a condition in which a sound in the head or ear is experienced subjectively but there is no corresponding external sound source. Tinnitus, which usually increases with age (1). Tinnitus can be caused by an underlying condition or disease, or it may result from exposure to external sound waves. Based on the cause, tinnitus can be classified into external ear tinnitus, middle ear tinnitus, inner ear tinnitus, neurological tinnitus, central tinnitus, tinnitus caused by the external auditory system, tinnitus caused by salicylic acid, and trauma-associated tinnitus. The pathogenesis of tinnitus is usually related to the posterior cochlear nerve, the sensory system, hormones, and central neurotransmitters (2). The base of the cochlea turns to 
the basement membrane to experience high-frequency sound, so hearing loss often starts from high-frequency and gradually develops to middle and low-frequency. At present, the diagnosis of tinnitus is mainly carried out from four aspects: nature, etiology, lesion location and quantification. When the tinnitus test is used for diagnosis, it is often considered that the tinnitus is mostly a single tone, and the loudness is often within the $5 \mathrm{~dB}$ hearing threshold (3). Studies have confirmed that the regular pure tone audiometry frequency of some tinnitus patients is within the normal range (4). But this cannot prove that the cochlear function of tinnitus patients has not been damaged.

At present, pure tone audiometry (PTA) is the most commonly used clinical hearing assessment method. The human auditory system can perceive sounds with a frequency of $20-20,000 \mathrm{~Hz}$, and the range of conventional pure tone audiometry is only $125-8,000 \mathrm{~Hz}$, while the extended high frequency audiometry (EHFA) can measure the hearing threshold of the human auditory system $10-20 \mathrm{kHz}$, so it can reflect the early stage of the cochlea damage (5). Therefore, EHFA is an important means for early evaluation of hearing impairment, is conducive to the early diagnosis and treatment of tinnitus patients, and is of great significance in clinical audiology (6).

Although there have been some clinical studies involving the diagnosis of tinnitus using the high-frequency portion of the hearing range, the quality of the literature is uneven and there is a lack of unified testing standards. For this reason, we performed a meta-analysis of randomized controlled trials (RCTs) involving EHFA in patients with tinnitus and evaluated the effect of EHFA by expanding the detection rate of hearing threshold (DR-HT) for tinnitus. The objective of this study was to provide a theoretical basis for the clinical diagnosis of tinnitus. We present the following article in accordance with the PRISMA reporting checklist (available at https://dx.doi.org/10.21037/apm-21-3060).

\section{Methods}

\section{Article inclusion and exclusion criteria}

The inclusion criteria were as follows: articles with an experimental group comprising patients clinically diagnosed with tinnitus and a control group involving people with normal hearing, as tested by pure tone audiometry (PTA), and no history of disease that could cause deafness; articles involving an RCT; articles published in English from a foreign or English database; articles in which the experimental and control groups were tested by EHFA or EHFA combined with conventional PTA; and articles with comparable baseline data for the experimental and control groups.

The exclusion criteria were as follows: articles which involved a non-RCT study, such as retrospective research; articles whose research objects were animals, and; unpublished literature, non-English literature, and literature with incomplete data.

\section{Article search}

We used 4 databases to search for RCT literature on EHFA in tinnitus patients: PubMed, Web of Science, China National Knowledge Infrastructure (CNKI), and Elsevier Science Direct. The search dates ranged from the database establishment date to February 2020. Literature search keywords consisted of subject words and free words, including "tinnitus", "extended high-frequency", "pure tone audiometry", "extended high-frequency audiometry", "PTA", "EHF", and "EHFA", and were connected with "and" or "or". The literature search was done independently by 2 researchers.

\section{Article screening}

Once the literature search was complete, the articles were screened independently by 2 researchers. The article bibliographies were first imported into NoteExpress 3.2.0 software to establish a database. After excluding duplicate documents, the 2 researchers manually screened the remaining articles. During manual screening, the researchers read the title and abstract of the articles and deleted those that did not meet the requirements. The researchers then read the full text of the remaining articles and using the inclusion and exclusion criteria, determined whether they could be included in the meta-analysis. If there was any disagreement between the 2 researchers, it was resolved through discussion. If they were unable to reach a consensus, a third party arbitrated.

\section{Data extraction}

Data extraction, including basic article information, research objects, intervention measures, outcome indicators, and other data, was carried out by the 2 researchers. Once the extraction was complete, a cross-examination was conducted. If there was disagreement, it was resolved 
through discussion. If the 2 researchers were unable to reach a consensus, a third party arbitrated. The content extracted from the articles included the following items: the title, first author, and publication date of the article; the age, gender, sample size, and baseline comparability of the research subjects; research intervention measures and control measures; and, research outcome indicators and research data.

\section{Quality evaluation of articles}

RCT bias risk assessment criteria provided in the Cochrane Handbook for Systematic Reviews for Interventions (version 5.0.2, 2008, Chapter 9) were adopted to assess the bias risk of the included articles. The assessment tool evaluated whether the study involved a randomized sequence, whether assignments were concealed, whether subjects were blinded, whether outcome assessors were blinded, whether the research data was complete, whether there was selective reporting, and whether there were other biases.

\section{Statistical analysis}

Review Manager 5.3 software was used to conduct a metaanalysis of the included articles and draw forest diagrams and funnel diagrams for the research indicators. As all the variables involved 2 categories, risk ratio (RR) was undertaken to describe the effect size, and a $95 \%$ confidence interval $(95 \% \mathrm{CI})$ was calculated. The main methods of sensitivity analysis include: changing the inclusion criteria (especially for controversial studies), excluding lowquality studies, and using different statistical methods/ models to analyze the same data. This study excluded lowquality articles for sensitivity analysis. Heterogeneity of the included articles was evaluated with $\mathrm{I}^{2}$. If $\mathrm{I}^{2}>50 \%$ and the source of the heterogeneity could not be explained, a random-effects model (REM) was adopted for analysis of the combined effect size, and if $\mathrm{I}^{2}<50 \%$, a fixed-effects model (FEM) was applied. The combined effect size adopted $U$ test and $95 \%$ CI. The $U$ test result was expressed as $\mathrm{P}$ value, and $\mathrm{P}<0.05$ indicated that the difference was statistically significant.

\section{Results}

\section{Results of article search}

Preliminary searches of the databases resulted in a total of
792 related articles, including 162 from PubMed, 269 from Web of Science, 202 from CNKI, and 159 from Elsevier Science Direct. After duplicate documents were eliminated using NoteExpress 3.2.0 software, 588 articles remained. Once the titles and abstracts were read and screened according to the inclusion criteria, there were 91 remaining articles. The 2 researchers read each of the remaining articles carefully, 14 articles that meet the requirements were included. After reading the full text, 3 articles with "too many people fall off" and 1 article with "research indicators were not clear" were further excluded. Finally, 10 articles were ultimately included in the meta-analysis (7-16). The publication dates varied from 2003 to 2020 . The 10 articles contained a total of 1,236 subjects and 2,361 ears, which included 620 subjects and 1,184 ears in the experimental group and 616 subjects and 1,177 ears in the control group. The baseline data of the study subjects were comparable. A flow chart illustrating the article search is shown in Figure 1, and the basic characteristics of the included articles are provided in Table 1.

\section{Bias risk assessment}

After risk of bias in the 10 articles was evaluated using the Cochrane Handbook for Systematic Reviews for Interventions (version 5.0.2), charts were drawn using Review Manager 5.3 software (as shown in Figures 2,3). The evaluation items for risk of bias included: randomized sequencing: 5 articles $(9,10,12,14,15)$ did not mention which randomization method was used, so they were defined as having an unclear risk of bias; assignment concealment: 10 articles (7-16) did not mention whether assignments were concealed, suggesting that they had an unclear risk of bias; subjects blinded: 1 article (13) mentioned that "subjects signed informed consents", suggesting a high risk of bias, and the remaining 9 articles $(7-12,14-16)$ did not report whether the subjects were blinded, so the risk of bias in these cases was unclear; 10 articles (7-16) did not mention whether outcome assessors were blinded, indicating that the risk of bias was unclear; data completeness: the outcome data of all 10 articles (7-16) were complete, indicating a low risk of bias; selective reporting: there was no selective reporting among the 10 articles (7-16), suggesting a low risk of bias; other risks of bias: for 3 articles $(13,14,16)$ it was impossible to judge whether there were other biases, suggesting an unclear risk of bias, and for 5 articles (7-11), the number of subjects in the experimental and control groups was inconsistent, suggesting a high risk of bias. 
Identification of studies via databases and registers

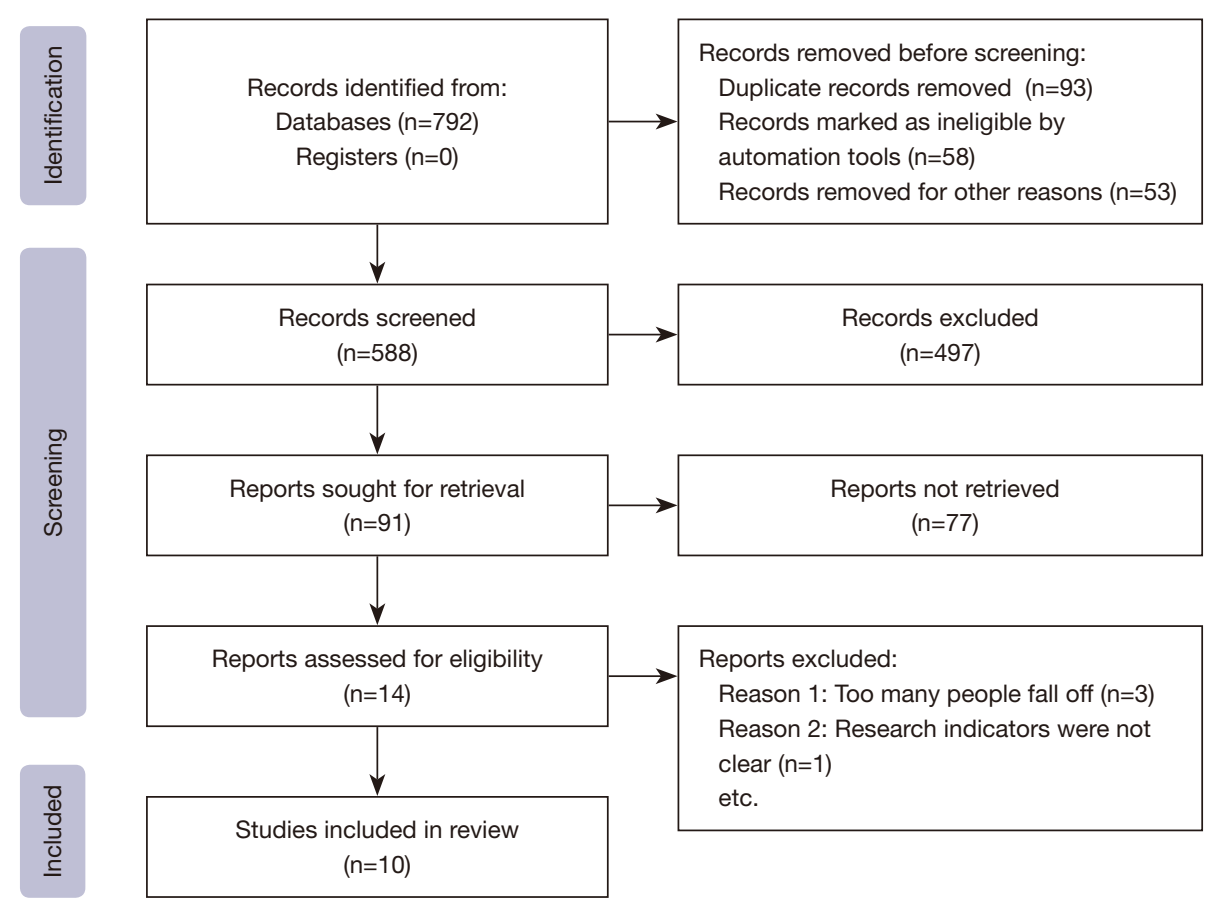

Figure 1 Flow chart for the article search.

\section{$\mathrm{DR}-\mathrm{HT}$ at $8 \mathrm{kHz}$}

A total of 6 documents $(7,10,12-14,16)$ reported on DRHT at $8 \mathrm{kHz}$, which included 679 subjects and 1,263 ears (374 subjects and 704 ears in the experimental group, 305 cases and 559 ears in the control group). There was a certain degree of heterogeneity among the included studies $\left(\mathrm{I}^{2}=97 \%\right.$ and $\left.\mathrm{P}<0.00001\right)$, and REM was used for analysis. The results are shown in Figure 4 [risk ratio $(\mathrm{RR})=0.97$, 95\% CI: $0.88-1.06, Z=0.72, P=0.47$ ] and suggest that there was no statistical difference between the experimental and control groups in DR-HT at $8 \mathrm{kHz}$.

\section{$D R-H T$ at $10 \mathrm{kHz}$}

A total of 8 articles $(7,9-14,16)$ reported on DR-HT at $10 \mathrm{kHz}$, which included 948 subjects and 1,795 ears (490 subjects and 934 ears in the experimental group, and 458 cases and 861 ears in the control group). There was a certain degree of heterogeneity among the included studies $\left(\mathrm{I}^{2}=97 \%\right.$ and $\left.\mathrm{P}<0.00001\right)$. The results of REM analysis are shown in Figure 5 (RR $=0.98,95 \%$ CI: $0.93-$ $1.03, \mathrm{Z}=0.97, \mathrm{P}=0.33$ ) and suggest that the experimental and control groups were not significantly different in DR$\mathrm{HT}$ at $10 \mathrm{kHz}$.

\section{$D R-H T$ at $12 \mathrm{kHz}$}

There were 7 documents $(7,9-11,13,14,16)$ reporting on DR-HT at $12 \mathrm{kHz}$, which included 768 subjects and 1,435 ears (400 subjects and 754 ears in the experimental group, and 368 cases and 681 ears in the control group). The heterogeneity among the included studies was visible $\left(\mathrm{I}^{2}=97 \%\right.$ and $\left.\mathrm{P}<0.00001\right)$, and $\mathrm{REM}$ was adopted for analysis. The results in Figure 6 ( $\mathrm{RR}=0.88,95 \%$ CI: $0.77-$ $1.01, \mathrm{Z}=1.85, \mathrm{P}=0.06$ ) indicate that there was no statistically significant difference between the 2 groups in DR-HT at $12 \mathrm{kHz}$.

\section{$D R-H T$ at $14 \mathrm{kHz}$}

A total of 7 documents $(7-9,11,13,14,16)$ reported on DR$\mathrm{HT}$ at $14 \mathrm{kHz}$, which included 645 subjects and 1,322 ears (323 subjects and 658 ears in the experimental group and 322 cases and 664 ears in the control group). The heterogeneity among the included studies was small $\left(\mathrm{I}^{2}=49 \%\right.$ 
Table 1 Basic characteristics of the included articles

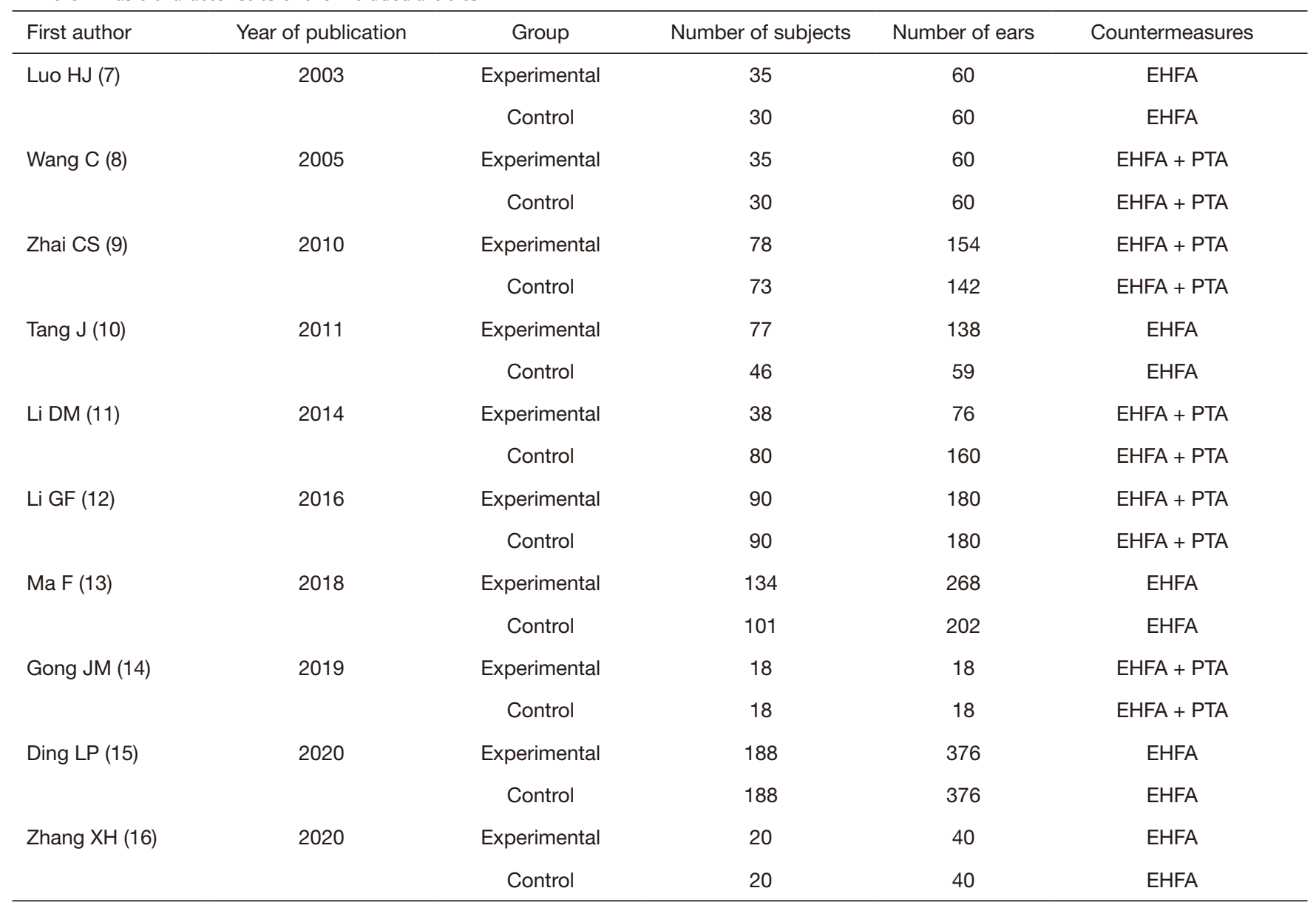

EHFA, extended high-frequency audiometry; PTA, pure tone audiometry.

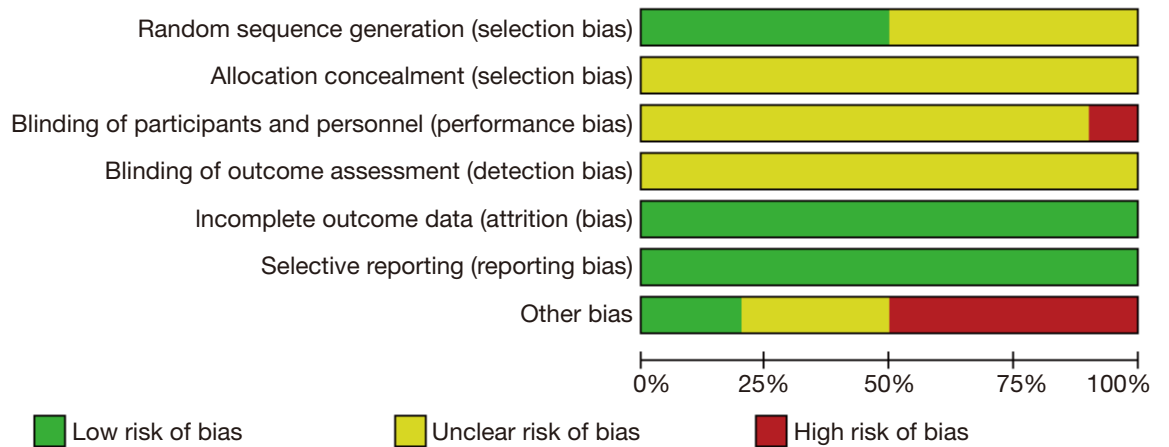

Figure 2 Bar graph for bias assessment of the included articles.

and $\mathrm{P}=0.08$ ), so FEM was applied for analysis. The results (Figure $7, \mathrm{OR}=0.21,95 \% \mathrm{CI}: 0.14-0.32, \mathrm{Z}=7.29$, and $\mathrm{P}<0.00001)$ indicate that there was a statistically significant difference in DR-HT between the 2 groups at $14 \mathrm{kHz}$.

\section{$\mathrm{DR}-\mathrm{HT}$ at $16 \mathrm{kHz}$}

Ten articles (7-16) reported on DR-HT at $16 \mathrm{kHz}$, which included 1,389 subjects and 2,667 ears (713 subjects and 
1,370 ears in the experimental group, and 676 subjects and 1,297 ears in control group). There was heterogeneity among the included studies $\left(\mathrm{I}^{2}=73 \%\right.$ and $\left.\mathrm{P}<0.0001\right)$, so REM was applied for analysis. The results are shown in Figure 8 [odds ratio (OR) $=0.14,95 \%$ CI: $0.07-0.27$, $\mathrm{Z}=5.96, \mathrm{P}<0.00001]$ and reveal an obvious difference in DR-HT at $16 \mathrm{kHz}$ between the 2 groups.

\section{$\mathrm{DR}-\mathrm{HT}$ at $18 \mathrm{kHz}$}

Seven articles $(7,8,11,13-16)$ reported on DR-HT at $18 \mathrm{kHz}$, which included 935 subjects and 1,814 ears (468 subjects and 898 ears in the experimental group, and 467 cases and 916 ears in the control group). There was heterogeneity among the included studies $\left(\mathrm{I}^{2}=68 \%\right.$ and $\left.\mathrm{P}=0.004\right)$. The REM analysis results are shown in Figure $9(\mathrm{OR}=0.13$, 95\% CI: $0.07-0.24, Z=6.50, \mathrm{P}<0.00001)$ and indicate that the experimental group showed an observable difference compared to the control group in DR-HT at $18 \mathrm{kHz}$.

\section{$\mathrm{DR}-\mathrm{HT}$ at $20 \mathrm{kHz}$}

A total of 7 articles $(7,8,11,13-16)$ reported on DR-HT at $20 \mathrm{kHz}$, which included 935 subjects and 1,814 ears (468 subjects and 898 ears in the experimental group, and 467 cases and 916 ears in the control group). The heterogeneity among the included studies was small $\left(\mathrm{I}^{2}=28 \%\right.$ and $\mathrm{P}=0.22)$. The FEM analysis results are shown in Figure 10 (OR $=0.17,95 \%$ CI: $0.12-0.23, Z=10.38$, $\mathrm{P}<0.00001)$ suggest that there was a statistically significant difference in DR-HT at $20 \mathrm{kHz}$ between the 2 groups.

\section{Analysis of publication bias}

Publication bias was evaluated using Review Manager 5.3 software, and the results are shown in Figure 11. The DR-HTs at $8,10,14,18$, and $20 \mathrm{kHz}$ were distributed within the CI, and the publication bias was low. The DRHT funnel charts at 12 and $16 \mathrm{kHz}$ had some scattered

Figure 3 Risk assessment of the included articles.

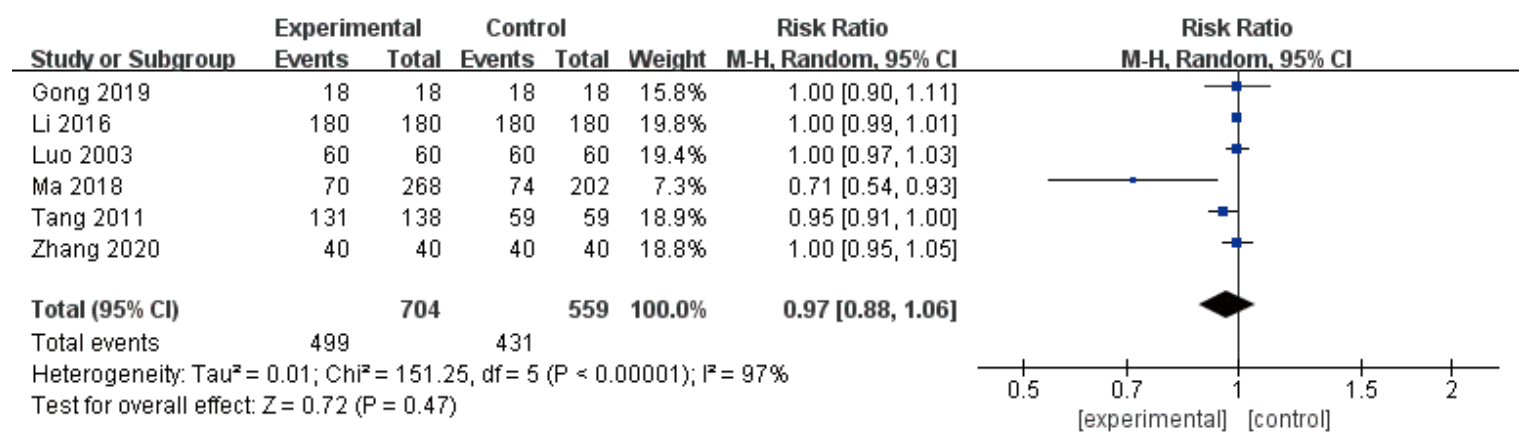

Figure 4 Forest diagram of detection rate of hearing threshold (DR-HT) at $8 \mathrm{kHz}$. 


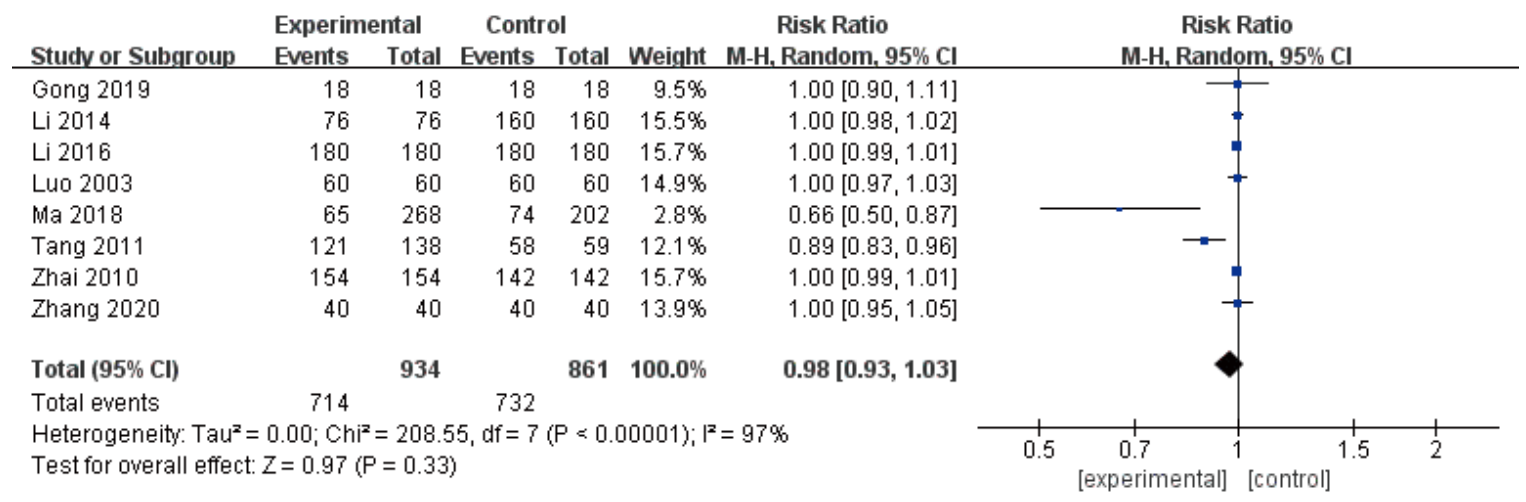

Figure 5 Forest diagram of detection rate of hearing threshold (DR-HT) at $10 \mathrm{kHz}$.

\begin{tabular}{|c|c|c|c|c|c|c|c|c|c|}
\hline \multirow{2}{*}{ Studv or Subgroup } & \multicolumn{2}{|c|}{ Experimental } & \multicolumn{2}{|c|}{ Control } & \multirow{2}{*}{ Weight } & \multirow{2}{*}{$\begin{array}{c}\text { Risk Ratio } \\
\text { M-H, Random, } 95 \% \mathrm{Cl}\end{array}$} & \multirow{2}{*}{\multicolumn{2}{|c|}{$\begin{array}{c}\text { Risk Ratio } \\
\text { M-H, Random, } 95 \% \mathrm{Cl}\end{array}$}} & \\
\hline & Events & & Events & lotal & & & & & \\
\hline Gong 2019 & 18 & 18 & 18 & 18 & $14.8 \%$ & $1.00[0.90,1.11]$ & & & \\
\hline Li 2014 & 66 & 76 & 160 & 160 & $15.2 \%$ & $0.87[0.79,0.95]$ & & - & \\
\hline Luo 2003 & 60 & 60 & 60 & 60 & $16.2 \%$ & $1.00[0.97,1.03]$ & & & \\
\hline Ma 2018 & 31 & 268 & 57 & 202 & $6.7 \%$ & $0.41[0.28,0.61]$ & & & \\
\hline Tang 2011 & 105 & 138 & 58 & 59 & $15.0 \%$ & $0.77[0.70,0.85]$ & & 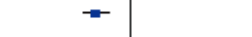 & \\
\hline Zhai 2010 & 148 & 154 & 142 & 142 & $16.1 \%$ & $0.96[0.93,1.00]$ & & - & \\
\hline Zhang 2020 & 40 & 40 & 40 & 40 & $16.0 \%$ & $1.00[0.95,1.05]$ & & & \\
\hline Total $(95 \% \mathrm{Cl})$ & & 754 & & 681 & $100.0 \%$ & $0.88[0.77,1.01]$ & & & \\
\hline Total events & 468 & & 535 & & & & & & \\
\hline $\begin{array}{l}\text { Heterogeneity: Tauz } \\
\text { Test for overall effect }\end{array}$ & $\begin{array}{l}0.03 ; \mathrm{Chi}^{-} \\
\mathrm{Z}=1.85(\end{array}$ & $\begin{array}{l}=208.7 \\
=0.06)\end{array}$ & $8, d f=6$ & $(P<0.0$ & $00001) ; I^{\prime}$ & $=97 \%$ & 0.2 & $0.5 \quad 1 \quad 2$ & 5 \\
\hline
\end{tabular}

Figure 6 Forest diagram of detection rate of hearing threshold (DR-HT) at $12 \mathrm{kHz}$.

\begin{tabular}{|c|c|c|c|c|c|c|c|c|c|}
\hline Stuck or Subgroup & \multicolumn{2}{|c|}{ Experimental } & \multicolumn{2}{|c|}{ Control } & Weight & $\begin{array}{c}\text { Odds Ratio } \\
\text { M-H, Fixed, 95\% Cl }\end{array}$ & \multicolumn{3}{|c|}{$\begin{array}{c}\text { Odds Ratio } \\
\text { M-H, Fixed, 95\% Cl }\end{array}$} \\
\hline Gong 2019 & 18 & 18 & 18 & 18 & & Not estimable & & & \\
\hline Li 2014 & 59 & 76 & 160 & 160 & $22.5 \%$ & $0.01[0.00,0.18]$ & $\longleftarrow$ & & \\
\hline Luo 2003 & 56 & 60 & 60 & 60 & $4.3 \%$ & $0.10[0.01,1.97]$ & & & \\
\hline Ma 2018 & 31 & 268 & 57 & 202 & $54.8 \%$ & $0.33[0.21,0.54]$ & & & \\
\hline Wang 2005 & 58 & 60 & 60 & 60 & $2.4 \%$ & $0.19[0.01,4.11]$ & & & \\
\hline Zhai 2010 & 140 & 154 & 142 & 142 & $13.2 \%$ & $0.03[0.00,0.58]$ & & & \\
\hline Zhang 2020 & 37 & 40 & 39 & 40 & $2.8 \%$ & $0.32[0.03,3.18]$ & & & \\
\hline Total $(95 \% \mathrm{Cl})$ & & 676 & & 682 & $100.0 \%$ & $0.21[0.14,0.32]$ & & & \\
\hline Total events & 399 & & 536 & & & & & & \\
\hline $\begin{array}{l}\text { Heterogeneity: } \mathrm{Chi}^{2} \\
\text { Test for overall effect }\end{array}$ & $\begin{array}{l}9.85, \mathrm{df}= \\
\mathrm{Z}=7.296\end{array}$ & $\begin{array}{l}(P=0 \\
<0.00\end{array}$ & $\begin{array}{l}.08) ;\left.\right|^{2}=4 \\
001)\end{array}$ & $49 \%$ & & & $\begin{array}{c}0.1 \\
\text { [experimental] }\end{array}$ & $\begin{array}{r}10 \\
\text { [control] }\end{array}$ & $\frac{1}{500}$ \\
\hline
\end{tabular}

Figure 7 Forest diagram of detection rate of hearing threshold (DR-HT) at $14 \mathrm{kHz}$.

points outside the CI, indicating that there was some publication bias.

\section{Discussion}

The incidence of tinnitus gradually increases with age and can cause upset, insomnia, and anxiety in patients. At present, there is no clinically effective drug for the treatment of tinnitus, and as the mechanism of tinnitus is unclear, early diagnosis is the basis for treatment (17). One of the characteristics of tinnitus is early high-frequency hearing impairment. Compared with conventional PTA, 


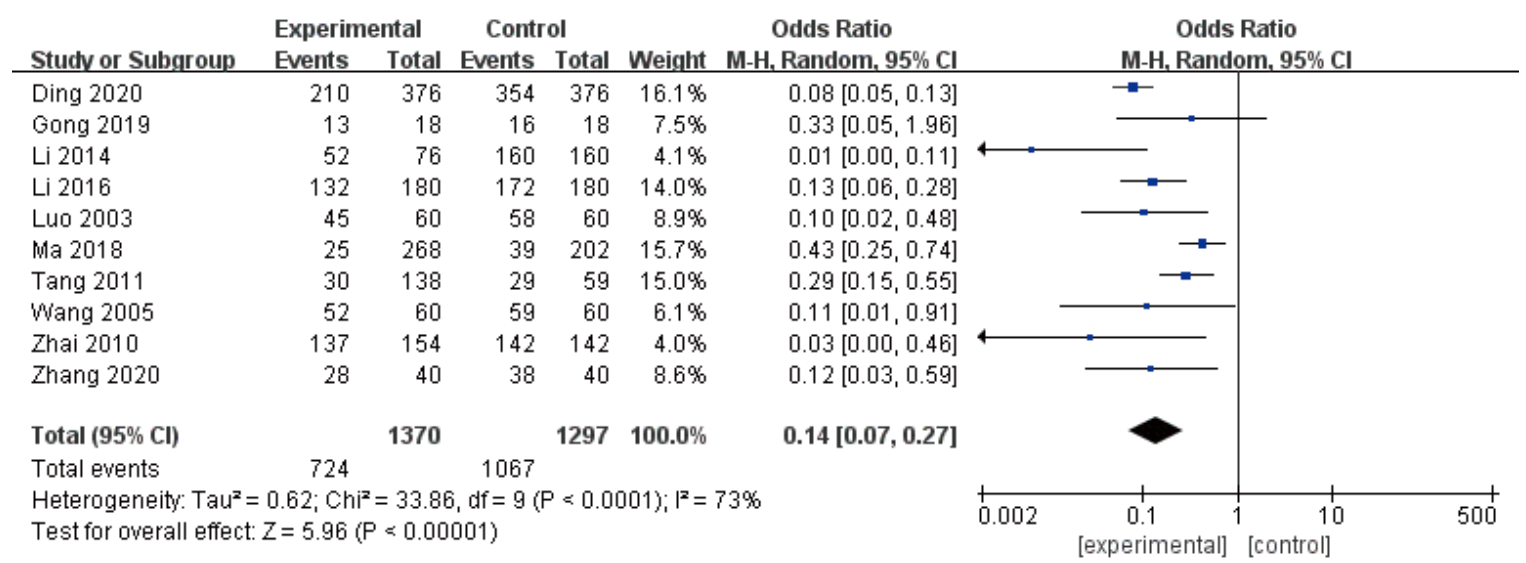

Figure 8 Forest diagram of detection rate of hearing threshold (DR-HT) at $16 \mathrm{kHz}$.

\begin{tabular}{|c|c|c|c|c|c|c|c|c|c|c|c|}
\hline Studv or Subgroup & \multicolumn{2}{|c|}{ Experimental } & \multicolumn{2}{|c|}{ Control } & Weight & $\begin{array}{c}\text { Odds Ratio } \\
\text { M-H, Random, } 95 \% \mathrm{Cl}\end{array}$ & \multicolumn{5}{|c|}{$\begin{array}{c}\text { Odds Ratio } \\
\text { M-H, Random, } 95 \% \mathrm{Cl}\end{array}$} \\
\hline Ding 2020 & 238 & 376 & 364 & 376 & $18.5 \%$ & $0.06[0.03,0.10]$ & & $\rightarrow-$ & & & \\
\hline Gong 2019 & 10 & 18 & 16 & 18 & $8.2 \%$ & $0.16[0.03,0.89]$ & & & & & \\
\hline Li 2014 & 46 & 76 & 153 & 160 & $15.5 \%$ & $0.07[0.03,0.17]$ & & & & & \\
\hline Luo 2003 & 38 & 60 & 52 & 60 & $15.2 \%$ & $0.27[0.11,0.66]$ & & & & & \\
\hline Ma 2018 & 16 & 268 & 38 & 202 & $18.5 \%$ & $0.27[0.15,0.51]$ & & $\longrightarrow$ & & & \\
\hline Wang 2005 & 48 & 60 & 57 & 60 & $11.2 \%$ & $0.21[0.06,0.79]$ & & & & & \\
\hline Zhang 2020 & 11 & 40 & 34 & 40 & $13.1 \%$ & $0.07[0.02,0.20]$ & & & & & \\
\hline Total $(95 \% \mathrm{Cl})$ & & 898 & & 916 & $100.0 \%$ & $0.13[0.07,0.24]$ & & & & & \\
\hline Total events & 407 & & 714 & & & & & & & & \\
\hline $\begin{array}{l}\text { Heterogeneity: } \mathrm{Tau}^{2} \\
\text { Test for overall effect }\end{array}$ & $\begin{array}{l}0.45 ; \mathrm{Chi}^{\circ} \\
\mathrm{Z}=6.50(\end{array}$ & $\begin{array}{l}=18.9 \\
<0.00\end{array}$ & $d f=6($ & $P=0.00$ & $04) ;\left.\right|^{2}=6$ & & 0.01 & $\begin{array}{c}0.1 \\
\text { [experimental] }\end{array}$ & 1 [control] & 10 & 100 \\
\hline
\end{tabular}

Figure 9 Forest diagram of detection rate of hearing threshold (DR-HT) at $18 \mathrm{kHz}$.

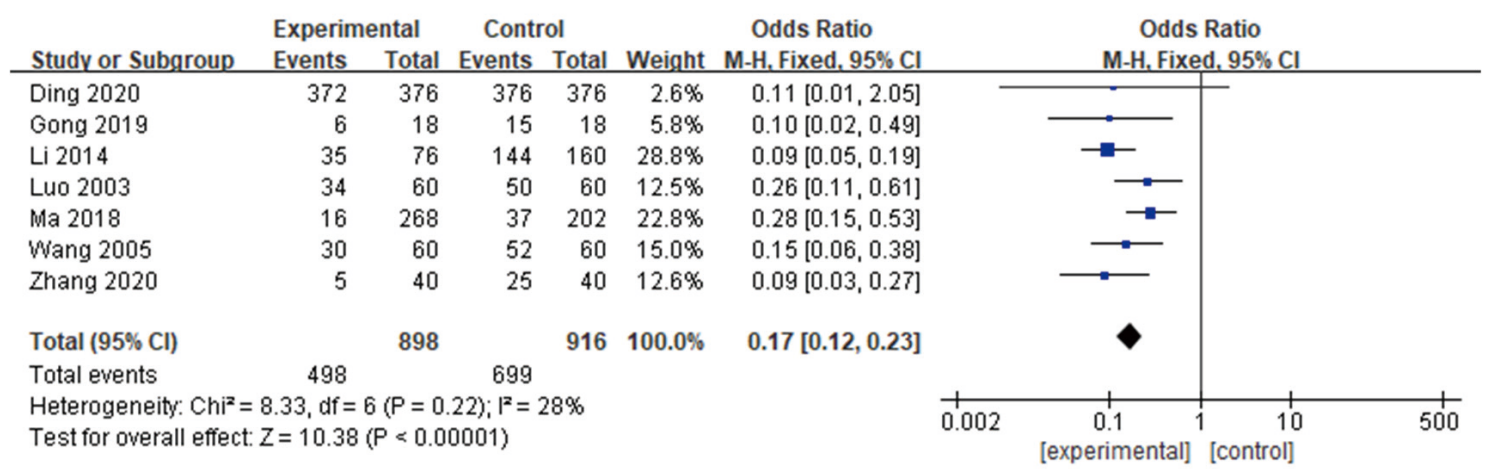

Figure 10 Forest diagram of detection rate of hearing threshold (DR-HT) at $20 \mathrm{kHz}$.

EHFA can detect hearing impairment earlier (18).

The results of our meta-analysis showed that at $8-12 \mathrm{kHz}$, the DR-HT of the experimental group was lower than that of the control group, but there was no strong statistical difference between the 2 groups. At $14-20 \mathrm{kHz}$, there was a statistically obvious difference in DR-HT between the 2 groups. As the frequency increased, the lower the DRHT, indicating that degeneration of the auditory system 

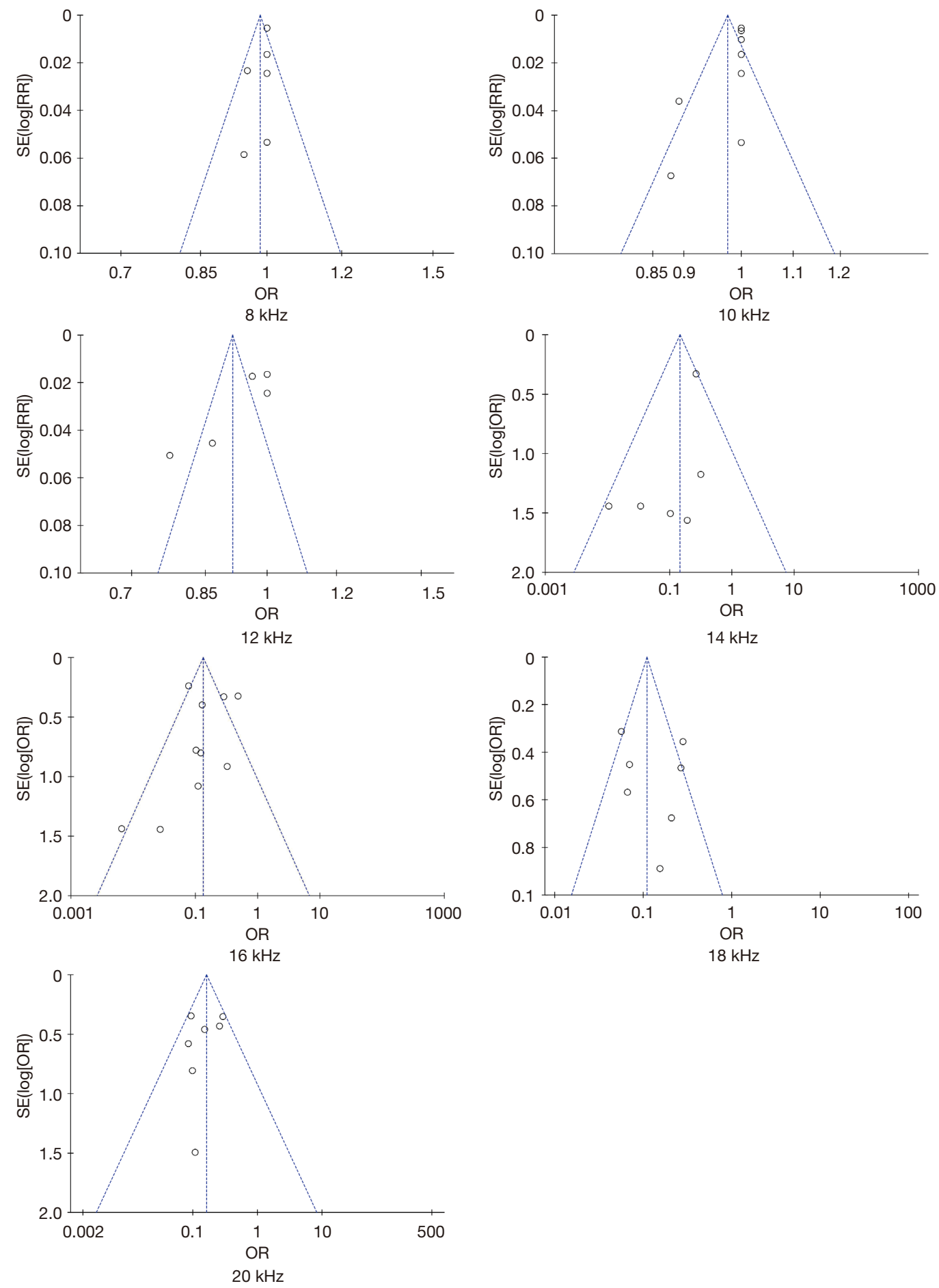

Figure 11 Funnel diagrams of detection rate of hearing threshold (DR-HT) at different frequencies.

in tinnitus patients starts with high frequencies and then moves to medium and low frequencies.

For the diagnosis of tinnitus, it is recommended that the doctor ask for a comprehensive medical history, improve the examination methods of the otolaryngology department, and detailed audiological examination methods. The severity 
of tinnitus can be graded through interviews, or the degree of tinnitus can be assessed by designing a tinnitus selfrating scale. This is conducive to doctors' targeted design of treatment methods. For the treatment of tinnitus, it can be eliminated by medication, dietary supplements, cochlear implants, transcranial electrical stimulation, vagus nerve stimulation, and acupuncture treatment (19-21). However, there is currently no way to completely cure subjective tinnitus. Therefore, treatments can help patients adapt to tinnitus and reduce the impact of tinnitus on daily life, such as sound therapy, hearing aids, and psychotherapy $(22,23)$.

At present, the cognition of tinnitus remains in a state of unknown cause and incurable. Moreover, the curative effect evaluation standard of tinnitus has not yet reached a uniform at home and abroad. Therefore, in future research, we hope to achieve new breakthroughs in the diagnosis and treatment of difficult diseases such as tinnitus through the perspective of traditional Chinese medicine.

\section{Conclusions}

Our meta-analysis of EHFA in tinnitus patients included 10 articles, which involved a total of 1,236 subjects and 2,361 ears. The results of the meta-analysis showed that there was no obvious statistical difference in DR-HT between tinnitus patients and healthy subjects at $8-12 \mathrm{kHz}$. At a frequency of $14-20 \mathrm{kHz}$, the DR-HT of tinnitus patients differed greatly from that of the normal population. As the frequency increased, DR-HT decreased. EHFA was effective in detecting tinnitus patients at high frequencies. Results of the meta-analysis in this study provided evidence for early hearing loss in tinnitus patients and a theoretical basis for the application of EHFA to the early clinical diagnosis of tinnitus patients.

This study had some limitations. The amount of included literature was low, resulting in a small sample size, and the high-frequency audiometry threshold of each frequency was not analyzed and evaluated. Therefore, in future work, more high-quality, large-sample experiments are needed for supplementary verification.

\section{Acknowledgments}

Funding: None.

\section{Footnote}

Reporting Checklist: The authors have completed the
PRISMA reporting checklist. Available at https://dx.doi. org/10.21037/apm-21-3060

Conflicts of Interest: All authors have completed the ICMJE uniform disclosure form (available at https://dx.doi. org/10.21037/apm-21-3060). The authors have no conflicts of interest to declare.

Ethical Statement: The authors are accountable for all aspects of the work in ensuring that questions related to the accuracy or integrity of any part of the work are appropriately investigated and resolved.

Open Access Statement: This is an Open Access article distributed in accordance with the Creative Commons Attribution-NonCommercial-NoDerivs 4.0 International License (CC BY-NC-ND 4.0), which permits the noncommercial replication and distribution of the article with the strict proviso that no changes or edits are made and the original work is properly cited (including links to both the formal publication through the relevant DOI and the license). See: https://creativecommons.org/licenses/by-nc-nd/4.0/.

\section{References}

1. Ryan D, Bauer CA. Neuroscience of Tinnitus. Neuroimaging Clin N Am 2016;26:187-96.

2. Lee HY, Kim SJ, Chang DS, et al. Tinnitus in the side with better hearing. Am J Otolaryngol 2019;40:400-3.

3. Dadoo S, Sharma R, Sharma V. Oto-acoustic emissions and brainstem evoked response audiometry in patients of tinnitus with normal hearing. Int Tinnitus J 2019;23:17-25.

4. Paken J, Govender CD, Pillay M, et al. Feasibility and first results of a prospective cohort study to investigate cisplatin-associated ototoxicity amongst cancer patients in South Africa. BMC Cancer 2021;21:822.

5. Rodríguez Valiente A, Roldán Fidalgo A, Villarreal IM, et al. Extended high-frequency audiometry $(9,000-$ $20,000 \mathrm{~Hz}$ ). Usefulness in audiological diagnosis. Acta Otorrinolaringol Esp 2016;67:40-4.

6. Song Z, Wu Y, Tang D, et al. Tinnitus Is Associated With Extended High-frequency Hearing Loss and Hidden High-frequency Damage in Young Patients. Otol Neurotol 2021;42:377-83.

7. Luo HJ, Yang J, Zhao JY, et al. High Frequency Audiometry and Its Significance in Pa-tients With Normal Hearing in Speech Frequency. Journal of Audiology and Speech Pa-thology 2003;11:96-8. 
8. Wang C, Zhang XR, Liu Y, et al. Function of extended high frequency audiometry in early diagnosis of hearing loss of noises and tinnitus. Journal of Harbin Medical University 2005;39:178-9.

9. Zhai CS, Liu B, Liu H, et al. Extended high frequency audiometry in coal miners. Chinese Journal of Otology 2010;8:303-6.

10. Tang J, Ji B, Liu L. Study of hearing loss in 200 patients with subjective tinnitus. Lin Chung Er Bi Yan Hou Tou Jing Wai Ke Za Zhi 2011;25:726-9.

11. Li DM, Tong JF, Yang RR, et al. Effect of extended high frequency audiometry on early detection of noise induced hearing impairment. Occupation and Health 2014;30:2217-9.

12. Li GF, Wang CH, Liu CB. The analysis of hearing results in 250 patients with tinnitus. Journal of Hebei Medical University 2016;37:806-808, 813.

13. Ma F, Gong S, Liu S, et al. Extended High-Frequency Audiometry $(9-20 \mathrm{kHz})$ in Civilian Pilots. Aerosp Med Hum Perform 2018;89:593-600.

14. Gong JM, Zhao WL, Wu YL, et al. The Acoustic Performance of Noise-induced Hidden Hearing Loss in Electrocochleography. Journal of Audiology and Speech Pathology 2019;27:172-6.

15. Ding LP, Meng ZL, Zheng Y. A Study of Extended High Frequencies with Normal Hear-ing Thresholds at Conditional Frequencies and Normal Otoacoustic Emission among Pri-mary Tinnitus Cases. Chinese Scientific Journal of Hearing and Speech Rehabilitation
2020;18:14-7.

16. Zhang XH, Zhao WL, Wang F, et al. Different Clinical Hearing Testing Methods in Early Detection of Noiseinduced Hidden Hearing Loss. Journal of Audiology and Speech Pathology 2020;28:273-6.

17. Martz E, Henry JA. Coping with tinnitus. J Rehabil Res Dev 2016;53:729-42.

18. Sulaiman AH, Husain R, Seluakumaran K. Hearing Risk among Young Personal Listening Device Users: Effects at High-Frequency and Extended High-Frequency Audiogram Thresholds. J Int Adv Otol 2015;11:104-9.

19. Coelho C, Tyler R, Ji H, et al. Survey on the Effectiveness of Dietary Supplements to Treat Tinnitus. Am J Audiol 2016;25:184-205.

20. Knipper M, van Dijk P, Schulze H, et al. The Neural Bases of Tinnitus: Lessons from Deafness and Cochlear Implants. J Neurosci 2020;40:7190-202.

21. Doi MY, Tano SS, Schultz AR, et al. Effectiveness of acupuncture therapy as treatment for tinnitus: a randomized controlled trial. Braz J Otorhinolaryngol 2016;82:458-65.

22. Sereda M, Xia J, El Refaie A, et al. Sound therapy (using amplification devices and/or sound generators) for tinnitus. Cochrane Database Syst Rev 2018;12:CD013094.

23. Tavanai E, Mohammadkhani G. A different view on the link between tinnitus and cognition; is there a reciprocal link? Int J Neurosci 2018;128:1188-98.

(English Language Editor: A. Muijlwijk)

Cite this article as: Peng F, Xiang Y, Xu H, Yin Q, Li J, Zou Y. Systematic review and meta-analysis of extended highfrequency audiometry in tinnitus patients. Ann Palliat Med 2021;10(12):12129-12139. doi: 10.21037/apm-21-3060 